\title{
A new viscoelastic mechanics model for the creep behaviour of fiber reinforced asphalt concrete
}

\author{
Chunshui Huang \\ College of Civil Engineering, Xuchang University, Xuchang 461000, China; School of Civil Engineering, Zhengzhou University, \\ Zhengzhou 450001, China \\ chunshuibuang@163.com
}

Fangtao Wang, Tao Gao

Henan Province Highway Engineering Bureau Group co., Ltd, Zhengzhou 450052, China

1092366742@qq.com,240286295@qq.com

\section{Danying Gao}

School of Civil Engineering, Zhengzhou University, Zhengzhou 450001, China

gdy@zzu.edu.cn

ABSTRACT. Based on the Burgers model, by adding a damper unit, this paper proposes a new viscoelastic model with five units and eight parameters to characterize the viscoelastic deformation of fiber reinforced asphalt concrete (FRAC). According to the creep tests of FRAC beams, this paper studies both the parameters in the model and the viscoelastic behaviour of FRAC with different fiber volume fraction and aspect ratio. In this model, this paper establishes the viscoelastic constitutive equation of asphalt concrete, which takes into account the impacts of fiber content characteristic parameter. Both the experimental study and theoretical analysis show that the new model has a high correlation with the results of creep experiment and plays a key role in describing the whole creep process of FRAC. The fiber content characteristic parameter can comprehensively reflect the effects of the fiber volume fraction and aspect ratio on the viscoelastic behaviour of FRAC. Within the range of this test, the optimum fiber volume fraction, fiber aspect ratio and fiber content characteristic parameter are $0.35 \%, 324$ and 1.13 , respectively.

KEYWORDS. Fiber reinforced asphalt concrete; Viscoelastic model; Viscoelastic performance; Creep test; Fiber content characteristic parameter.

\section{OPEN ACCESS}

Citation: Huang, C., Wang, F., Gao, T., Gao, D., A new viscoelastic mechanics model for the creep behaviour of fibre reinforced asphalt concrete, Fratturaed Integrità Strutturale, 45 (2018) 108-120.

Received: 22.03 .2015

Accepted: 21.04 .2018

Published: 01.07.2015

Copyright: (C) 2018 This is an open access article under the terms of the CC-BY 4.0, which permits unrestricted use, distribution, and reproduction in any medium, provided the original author and source are credited.

\section{INTRODUCTION} typical viscoelastic materials. The various viscoelastic mechanics models can be formed by combining the basic 
viscoelastic mechanics elements such as spring and dampers [1-4]. Generally, the model parameters can be obtained by uniaxial compression creep test, triaxial compression creep test and beam bending creep test [5-11]. Besides, the influence of stress level, temperature and fiber content on the model parameters and the viscoelastic behavior of AC can also be achieved by above mentioned tests.

Over the years, many models have been developed to study the properties of AC and FRAC. For instance, the Burgers model [2] reveals that the permanent deformation of FRAC has a linear positive correlation with loading time and a linear negative correlation with viscosity, and that the viscosity increases with the extension of loading time. However, some of the modelling results differ from the deformation features of FRAC during creep, such as the negative correlation between permanent strain and loading time, the absence of constant velocity creep, and the accelerated creep process. In the four-element five-parameter model [2], the viscosity increases with loading time, and the permanent strain increment exhibits an opposite trend; under the infinite loading time, the permanent strain increment gradually approximates zero; in this case, the deformation features are close to those of constant velocity creep rather than those of FRAC during accelerated creep. Reference [8] examines the effects of fiber volume ratio and length-diameter ratio on AC viscoelasticity, but fails to characterize the overall effects of the two ratios with one parameter. Thus, the understanding of the viscoelastic behavior of AC and FRAC is still very limited.

In this paper, a new viscoelastic mechanics model with five units and eight parameters for FRAC was employed by analyzing the viscoelastic behavior of FRAC. The parameters of this model were obtained by beam bending creep tests with different fiber volume fraction and aspect ratio. The efficiency and validity of the present model were demonstrated by comparing the results of the model with those of Burgers model and modified Burgers model. At last, the effects of fiber volume fraction and fiber aspect fraction on the model parameters and the viscoelastic properties at loading and unloading creep stage of AC were studied by using the model.

\section{VISCOELASTIC MECHANIC MODEL WITH FIVE UNITS AND EIGHT PARAMETERS}

I $\mathrm{t}$ is known that $\mathrm{AC}$ exhibits high time-dependent deformation process which called creep process and can be divided into two stages: loading creep and unloading creep. The curve of the whole creep process of FRAC beam bending in Fig. 1 shows that the creep deformation in loading is similar to that of AC and it also includes three stages [1,3]:

(1) The stage of deceleration creep during the beginning of loading (migration period). Polyester fiber reinforced asphalt concrete (PFRAC) beam produces instantaneous elastic deformation under creep loading in this period, and the span deflection increases with time, while the creep rate gradually decreases with time.

(2) The stage of constant speed creep (stable creep period). Creep deformation continues to increase with time elapsing, while the incremental rate of creep deformation keeps constant approximately and the deformation-time curve is a straight line.

(3) The stage of accelerating creep (undermine period). With the deformation gradually increasing, the slippage among the beam internal aggregates begins to take place and the cracks found in the bottom of test specimen begin to propagate gradually. It is noted that creep rate increases gradually and the deformation-time curve deviates from the straight line.

An inflection point can be easily observed in the transition from the stable creep to accelerated creep in the deformationtime curve, and the corresponding loading time at the inflection point is named rheology time Ft of FRAC [11]. Obviously, $\mathrm{Ft}$ is the time that the creep rate reduced to the minimum and the start time that FRAC begin to enter the stage of the accelerated creep. The creep rate increases after the inflection point of time. During the stage of creep unloading, the elastic deformation immediately recovered and the viscoelastic deformation gradually restored with time. However, the plastic deformation cannot be restored and become permanent deformation.

Both Burgers model and modified Burgers model are widely used to describe the viscoelastic deformation characteristics of AC in engineering. Burgers model is a combination of two springs and two dampers [2], as shown in Fig. 2. The creep equation of the model in loading stage is:

$$
\varepsilon(t)=\sigma_{0}\left(\frac{1}{\mathrm{E}_{1}}+\frac{t}{\eta_{1}}+\frac{1-e^{-t \tau}}{\mathrm{E}_{2}}\right)
$$

The creep rate is:

$$
\dot{\varepsilon}(t)=\sigma_{0}\left(\frac{1}{\eta_{1}}+\frac{e^{-t \tau}}{\eta_{2}}\right)>0
$$




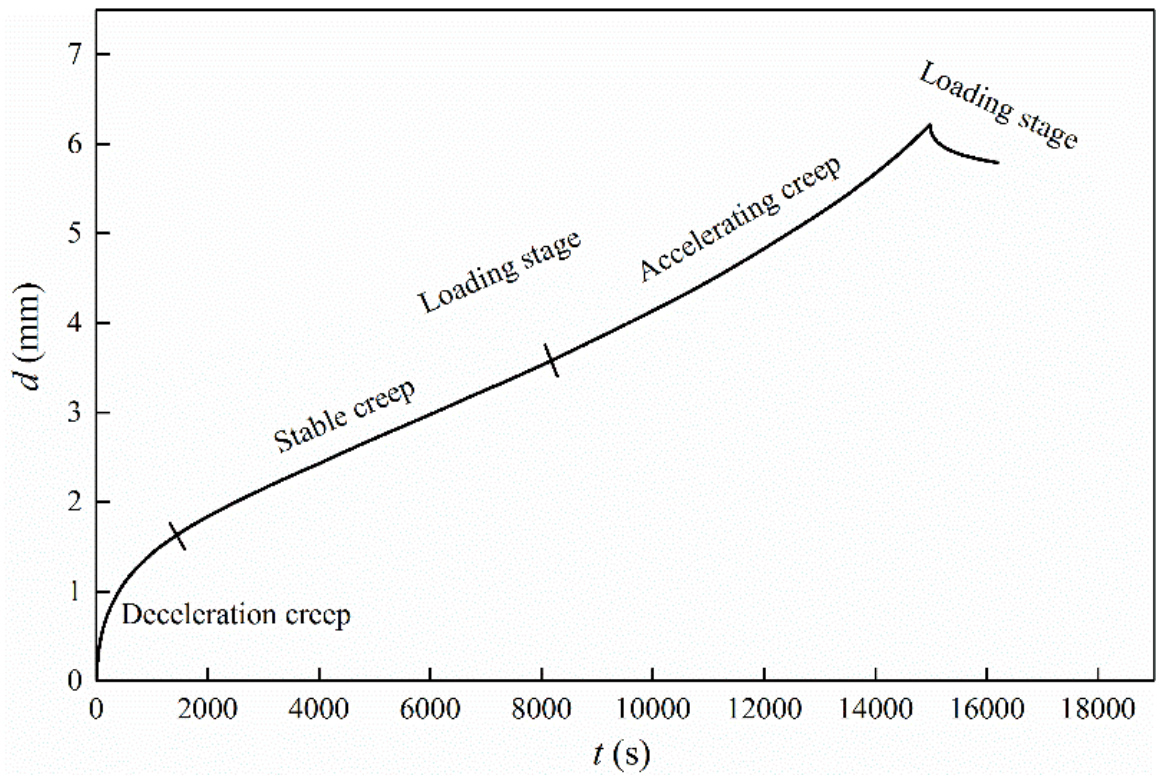

Figure 1: Typical creep curve.

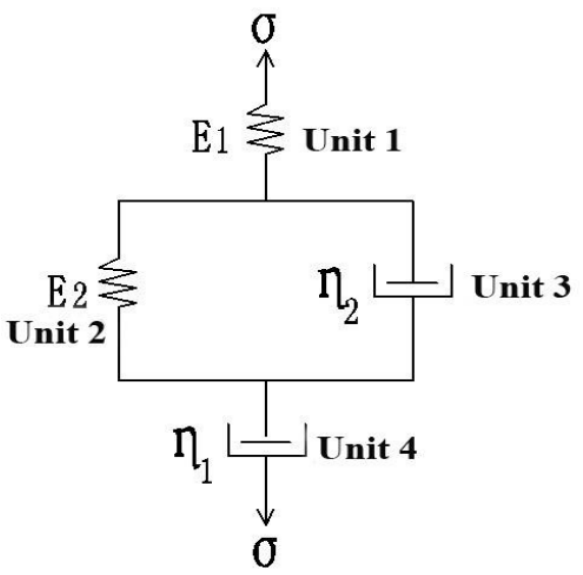

Figure 2: Burgers model.

The creep acceleration is:

$$
\ddot{\varepsilon}(t)=\frac{-\sigma_{0} \mathrm{E}_{2} e^{-t \tau}}{\eta_{2} \eta_{2}}<0
$$

where $\sigma_{0}$ is the loading stress; $t$ is the loading time; $\mathrm{E}_{1}$ and $\mathrm{E}_{2}$ are the elastic modulus of elements 1 and 2, respectively; $\eta_{1}$ and $\eta_{2}$ are the viscosities of elements 3 and 4 , respectively; and $\tau=E_{2} / \eta_{2}$.

In Eqn. (1), the permanent deformation of FRAC is a linear function of time $t$ and the reciprocal of viscosity $1 / \eta_{1}$. With time elapsing, the viscosity increases while the permanent stress increment decreases. Both the stages of the stable creep and accelerated creep do not exist during the creep process. There is no inflection point in the creep deformation-time curve noticing from Eqn. (2) and (3). Therefore, the model does not present the rheological time characteristics of viscoelastic material and does not match the creep deformation characteristics of FRAC.

Based on Burgers model, a modified model with four-unit and five-parameter was proposed through a nonlinear modification on the viscosity of the external damper with the viscous flow deformation characteristics of material [2], as shown in Fig. 3. The viscosity of the external damper in this model is: 


$$
\eta_{1}(t)=A e^{B t}
$$

During the loading stage, equations of the creep, the creep rate and the creep acceleration can be expressed as:

$$
\begin{aligned}
& \varepsilon(t)=\sigma_{0}\left(\frac{1}{\mathrm{E}_{1}}+\frac{1-e^{-B t}}{A B}+\frac{1-e^{-t \tau}}{\mathrm{E}_{2}}\right) \\
& \dot{\varepsilon}(t)=\sigma_{0}\left(\frac{e^{-B t}}{A}+\frac{e^{-t \tau}}{\eta_{2}}\right)>0 \\
& \ddot{\boldsymbol{\varepsilon}}(t)=-\sigma_{0}\left(\frac{B e^{-B t}}{A}+\frac{\mathrm{E}_{2} e^{-t \tau}}{\eta_{2} \eta_{2}}\right)<0
\end{aligned}
$$

where $\eta_{1}(\mathrm{t})$ is the viscosity of external viscous component of modified model; $A$ and $B$ are the viscosity parameters of viscous elastic element 4, as shown in Fig.3.

From Eqn. (4) and (5), it can be found that with the loading time increasing, the viscosity of element 4 increases and the permanent strain decreases. When the loading time tends to infinity, the strain increment tends to zero. The equations can be used to characterizes the consolidation effect of FRAC [4], which is similar to the deformation characteristics of stable creep stage. However, Eqn. (4) and Eqn. (5) still cannot describe the deformation characteristics of the accelerated creep stage of FRAC. From Eqn. (6) and Eqn. (7), the demarcation point of stable creep and accelerated creep do not present in the curve of creep deformation and time of FRAC, so the model cannot be used to describe the rheological time characteristics of viscoelastic material.

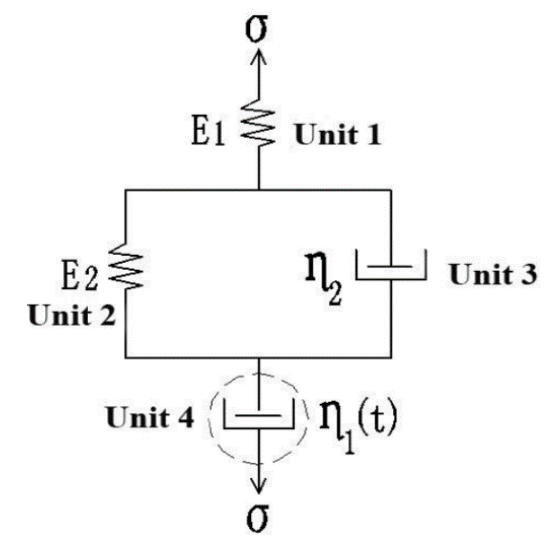

Figure 3: Modified Burgers model.

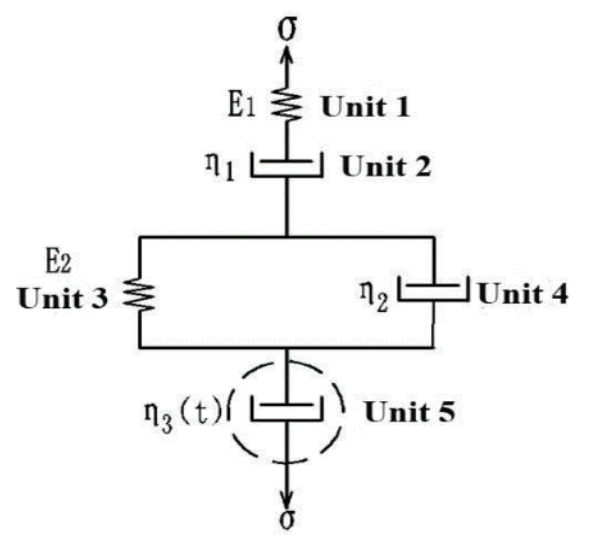

Figure 4: Five units and eight parameters model

In order to effectively describe the deformation feature of the whole creep process of FRAC and construct the rheological time parameters of viscoelastic material, a viscoelastic model with five units and eight parameters by adding a viscous component 5 is adopted based on Burgers model, as shown in Fig. 4. In this model, the viscosity of element 5 increases with time firstly and then decreases, that is:

$$
\eta_{3}(t)=\frac{\eta_{0}}{a t^{2}-b t+c}
$$

where, $\eta_{0}$ is the initial viscosity of element $5 ; \alpha, b$ and $c$ are the viscosity parameters of element 5 , moreover, $\alpha>0, b>0$, c $>0$, and. $\mathrm{b}^{2}-4 \alpha c<0$

The creep equation of the model with five units and eight parameters can be expressed as For the loading stage, 


$$
\varepsilon(t)=\sigma_{0}\left(\frac{1}{\mathrm{E}_{1}}+\frac{t}{\eta_{1}}+\frac{1-e^{-t \tau}}{\mathrm{E}_{2}}+\frac{\frac{a}{3} t^{3}-\frac{b}{2} t^{2}+c t}{\eta_{0}}\right)
$$

For the unloading stage,

$$
\varepsilon(t)=\sigma_{0}\left[\frac{t_{0}}{\eta_{1}}+\frac{\left(1-e^{-t_{0} \tau}\right) e^{-\tau\left(t-t_{0}\right)}}{\mathrm{E}_{2}}+\frac{\frac{a}{3} t_{0}^{3}-\frac{b}{2} t_{0}^{2}+c t_{0}}{\eta_{0}}\right]
$$

The creep speed during the loading stage is

$$
\dot{\varepsilon}(t)=\sigma_{0}\left(\frac{1}{\eta_{1}}+\frac{e^{-t \tau}}{\eta_{2}}+\frac{a t^{2}-b t+c}{\eta_{0}}\right)
$$

For the creep accelerator during the loading stage is

$$
\ddot{\varepsilon}(t)=\sigma_{0}\left(\frac{-\mathrm{E}_{2} e^{-t \tau}}{\eta_{2} \eta_{2}}+\frac{2 a t-b}{\eta_{0}}\right)
$$

where $\mathrm{t}_{0}$ is the total loading time.

In Eqn. (12), if $\vec{\varepsilon}(\mathrm{t})=0$, then

$$
t-\frac{b}{2 a}=\frac{\eta_{0} \mathrm{E}_{2}}{2 a \eta_{2} \eta_{2}} e^{-t \tau}
$$

$t^{*}$ in Eqn. (13) can be solved by Newton iterative method. Obviously, if $0<t<t^{*}$, then $\varepsilon>0, \dot{\varepsilon}>0$ and $\ddot{\varepsilon}<0$. If

$t>t^{*}$, then $\varepsilon>0, \dot{\varepsilon}>0$ and $\ddot{\varepsilon}<0$. So $t^{*}$ is the onset time of inflection point in the curve of creep strain and time, and is the demarcation point between the stable creep and the accelerated creep. Also, the creep rate become the minimum at $t^{*}$. After this point, the creep speed gradually increases and the rheological time of FRAC $F_{t}=t^{*}$. This model theoretically constructs the demarcation point between stable creep and accelerated creep, which cannot be seen in Burgers model and modified Burgers model, and it matches the characteristics of typical creep deformation and time curve, as shown in Fig. 1.

\section{FRAC Viscoelastic Analysis and Validation of The Model Parameters}

$\mathrm{I}$ $\mathrm{n}$ the model with five units and eight parameters of FRAC, the resistance to elastic deformation is stronger as E1 gets larger. In the condition of same load and same time with increases, the permanent deformation decreases, and the resistance to viscous flow deformation tends to be stronger. When the relaxation time becomes larger, the increase of viscous flow deformation over time becomes slower, and then FRAC has a greater ability to resist rutting deformation. When the delay time becomes larger, the deformation development over time becomes slower, and then the resistance to viscoelastic deformation of FRAC becomes greater. When $\mathrm{b}$ is larger, a becomes smaller, while b becomes larger resulting in a larger rheological time, and then the resistance to viscous flow deformation of FRAC becomes stronger [12].

To verify the validity of the model expressed in Eqn. (9) and (10), the creep test of FRAC was carried out. A-70 asphalt and polyester fiber (PF) with various aspect ratios and volume fractions were used in this test. The length of polyester fiber is $3 \mathrm{~mm}, 9 \mathrm{~mm}$ and $12 \mathrm{~mm}$ respectively, the ratio of length to diameter is 162,486 and 649 , and the ratio of fiber to mineral mass is $0.2 \%$. The volume ratio of fiber is $0.35 \%$; For polyester fiber with length of $6 \mathrm{~mm}$, the ratio of length to diameter is 324 , and the fiber content is $0.1 \%, 0.2 \%, 0.3 \%$ and $0.4 \%$ respectively, and the corresponding fiber volume 
ratio is $0.17 \%, \quad .0 .35 \%, \quad 0.52 \%$ and $0.69 \%$, respectively. According to JTJ E20-2011 [13], the optimum asphalt content $(\mathrm{OAC})$ of matrix asphalt mixture, fiber aspect fraction and volume fraction of asphalt mixes were determined. Rolling molding the test specimen of $300 \mathrm{~mm} \times 300 \mathrm{~mm} \times 50 \mathrm{~mm}$, and then were cut into a $250 \mathrm{~mm} \times 30 \mathrm{~mm} \times 35 \mathrm{~mm}$ beam specimen. $15^{\circ} \mathrm{C}$ creep tests were performed by using a multifunctional material testing machine. The creep load is $10 \%$ of the beam bending failure load in the same condition, as shown in Fig. 5. Span deflection for the creep test of small beams is collected by using a dial gauge connected to the data acquisition system. Then the span deflection-time curve and the flexural tensile strain-time curves were drawn. When the beam specimens enter into the stage of accelerated creep stage then unload, and the test data were continued collecting for $30 \mathrm{~min}$. Based on the results of the creep test and assumed initial values of the model parameters in Eqn. (9) and (10), the nonlinear method of Origin 8.5 is used to obtained a best fitting between the theoretical results of the mechanical model and those from tests. The fitting effect is controlled by adjusting the model parameters. If the results match well, the viscoelastic parameters of the mechanical model can be achieved.

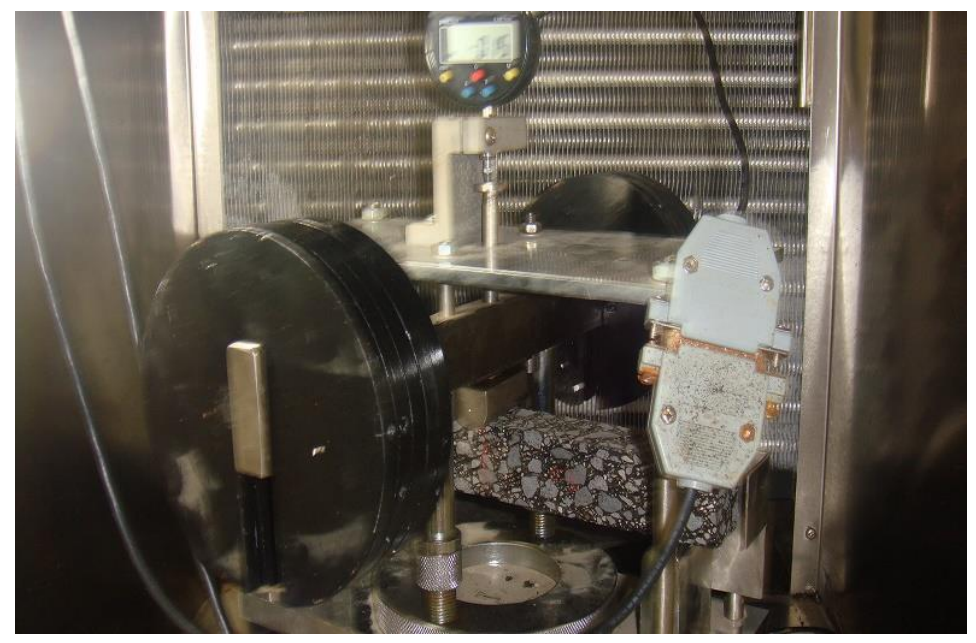

Figure 5: Creep test.

\section{RHEOLOGICAL TIME}

$\mathrm{R}$ heological time from Eqn. (13) and the rheological time corresponding to the creep stability based on the measured creep deformation-time curves are listed in Tab. 1. It can be seen that the present model can calculate the rheological time efficiently and accurately, and the relative error is less than $10 \%$ between the values calculated by the present model and results from the tests. The rheological time is the start time of the destruction of AC under creep loads [1], the larger the value is, the longer the time taken to deform the test piece is and the stronger the ability to resist deformation of $\mathrm{AC}$ is. The test results show that, when the fiber volume fraction is $0.35 \%$ and the aspect ratio is 324 , the rheological time of FRAC is the largest and FRAC has the best resistance to deformation. The variation of creep strain-time curves is shown in Fig. 6. It can be observed that when fiber volume fraction is $0.35 \%$ and the aspect ratio of fiber is 324, its curve is lower than others, and it means that FRAC has the best resistance to deformation at this moment. It is in accordance with the resistance to deformation from the present model based on the rheological time.

Tab. 1 also shows the results of Burgers model and modified Burgers model. In comparison, the data from the present model is the closest to that of the stage of creep load among the three models, and the data of Burgers model has the largest deviation from the test data. The fitting curves of FRAC creep stain-time by using Origin8.5 software is shown in Fig. 7.

It can be seen that the fitting curve of the Burgers model during the stage of deceleration creep is below the test curve, and model characterization of FRAC creep deformation is less than the actual deformation. In the stage of stable creep model, the model curve is above the experimental curve, and the creep deformation of model characterization is greater than that of the actual deformation. In the stage of accelerating creep, the deformation of model characterization is less than the actual deformation of AC and model curve is below the experimental curve. It should be noticed that the difference between the test curve and the model curve will be more significant until specimen fracture. The fitting curve from the modified Burgers and that from Burgers are somewhat alike in relation to the test curve, while the difference is 
that the creep strain-time curve of modified Burgers model is closer to the test curve in the stages of decelerating creep and stable creep, and the modified Burgers model can better describe deceleration and constant velocity creep deformation characteristics of FRAC. The fitting curve of the new model almost coincides with the measured test curve. The present model greatly increases the fitting accuracy and can describe the viscoelastic deformation characteristics of the whole creep process of FRAC very well.

\begin{tabular}{lllcccccc}
\hline & & \multicolumn{7}{c}{ Calculation rheology time /s } \\
$V_{f}$ & $R_{a}$ & $\begin{array}{c}\text { Test } \\
\text { rheology } \\
\text { time } / \mathrm{s}\end{array}$ & $\begin{array}{c}\text { Burgers } \\
\text { model }\end{array}$ & $\begin{array}{c}\text { Modified } \\
\text { Burgers } \\
\text { model }\end{array}$ & $\begin{array}{c}\text { Five units and } \\
\text { eight } \\
\text { parameters } \\
\text { model/s }\end{array}$ & $\begin{array}{c}\text { Burgers } \\
\text { model }\end{array}$ & $\begin{array}{c}\text { Modified } \\
\text { Burgers } \\
\text { model }\end{array}$ & $\begin{array}{c}\text { Five units and } \\
\text { eight parameters } \\
\text { model }\end{array}$ \\
\hline 0 & 0 & 1450 & $/$ & $/$ & 1320 & 0.99912 & 0.99930 & 0.99975 \\
0.17 & 324 & 7500 & $/$ & $/$ & 7332 & 0.99815 & 0.99930 & 0.99966 \\
0.35 & 324 & 10200 & $/$ & $/$ & 10996 & 0.99540 & 0.99926 & 0.99988 \\
0.52 & 324 & 7200 & $/$ & $/$ & 7739 & 0.99923 & 0.99958 & 0.99996 \\
0.69 & 324 & 3200 & $/$ & $/$ & 2986 & 0.99913 & 0.99925 & 0.99984 \\
0.35 & 162 & 5500 & $/$ & $/$ & 6045 & 0.99936 & 0.99951 & 0.99987 \\
0.35 & 486 & 9000 & $/$ & $/$ & 8532 & 0.99746 & 0.99924 & 0.99990 \\
0.35 & 649 & 8000 & $/$ & $/$ & 7501 & 0.99118 & 0.99905 & 0.99981 \\
\hline
\end{tabular}

Table 1: Relationship between model index with fiber content and fiber aspect.

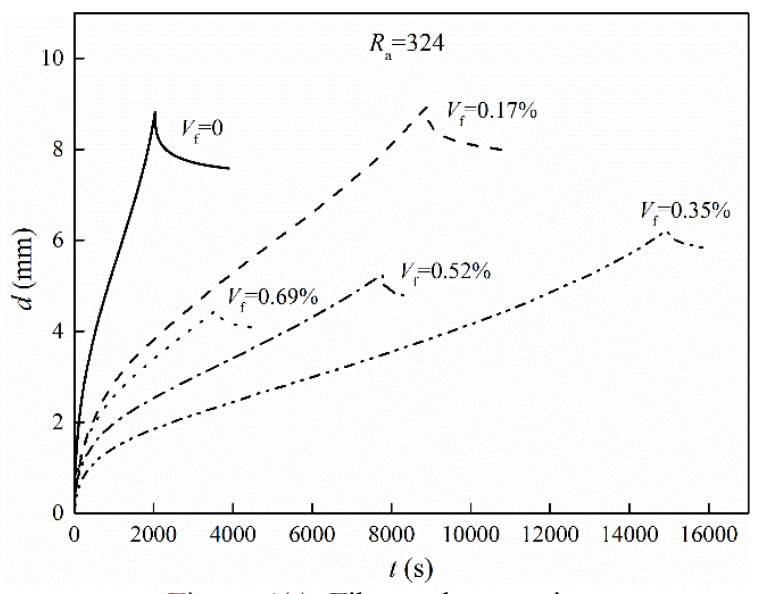

Figure 6(a): Fiber volume ratio.

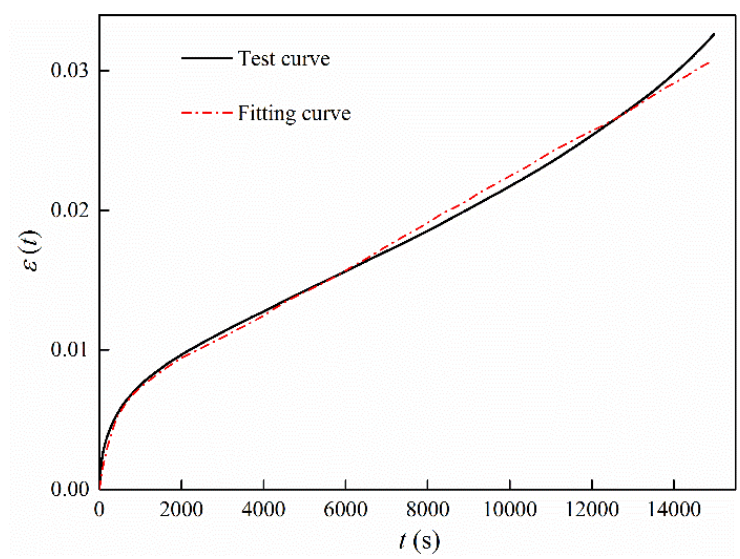

Figure 7(a): Burgers model.

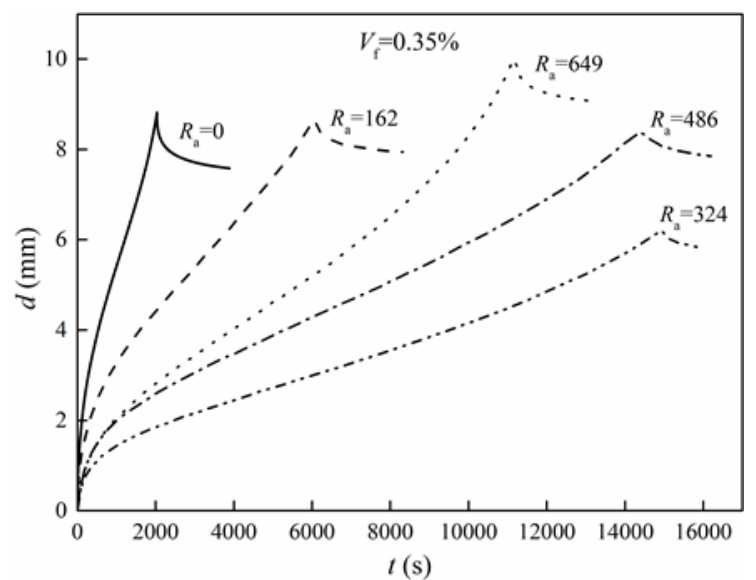

Figure 6(b): Fiber aspect ratio.

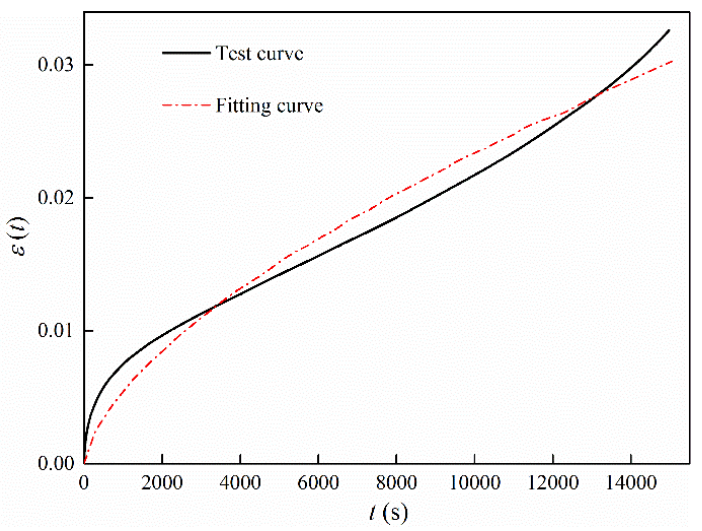

Figure 7(b): Modified Burgers model. 


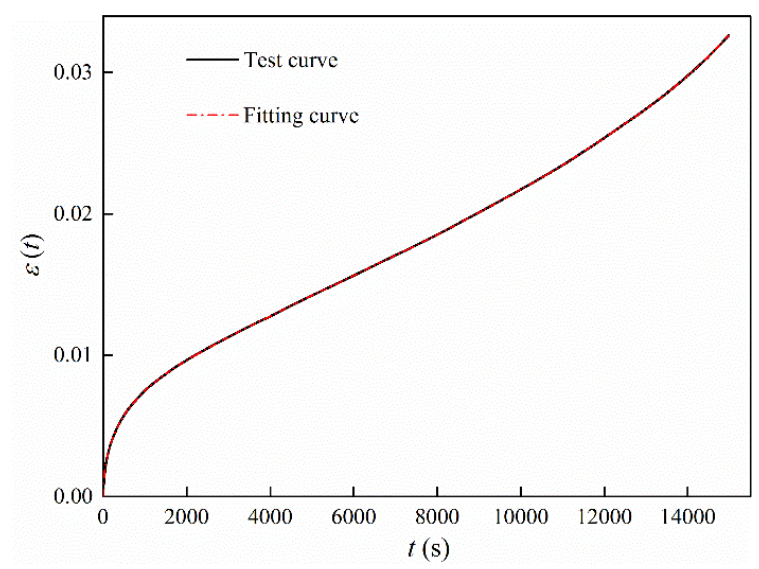

Figure 7(c): Five units and eight parameters model.

\section{LOAD PHASE}

$\mathrm{T}$

1 he model parameters of FRAC in Eqn. (9) with different $V_{f}$ and $R_{a}$ were obtained from fitting the experimental data and listed in Tab. 2. It can be noticed that the $E_{1}$ and $\eta_{1}$ firstly increase and then decrease with the increase of $V_{f}$. When $V_{f}$ is $0.35 \%, E_{1}$ and $\eta_{1}$ are at peak values and FRAC has stronger resistance to both elastic deformation and permanent deformation. When $V_{f}$ is $0.69 \%, E_{1}$ and $\eta_{1}$ of FRAC are smaller than those of AC matrix. It indicates that fiber can enhance the elasticity and viscosity of the FRAC only with proper fiber volume fraction; excessive fiber may decrease the resistance of $\mathrm{AC}$ to the instantaneous elastic and viscous flow deformation. Both the relaxation time $\eta_{1} / E_{1}$ and the delay time $\eta_{2} / E_{2}$ firstly increase and then decrease with the increase of $V_{f}$. It means that a certain $V_{f}$ can increase the anti-rutting deformation capacity of FRAC. When $V_{f}$ is $0.35 \%$, both the relaxation time and delay time are at maximum, and FRAC has the highest temperature stability at this time [12]. The $a$ firstly decrease and then increase with the increase of $V_{f}$, while $\eta_{0}, \mathrm{~b}$, and $b / 2 a$ firstly increase and then decrease with increase of $V_{f}$. It indicates that rheological time of FRAC first increases and then decreases with increasing $V_{f}$. It is worth mentioning that when $V_{f}$ is $0.35 \%$, rheological time reaches the maximum value and FRAC show the best resistance to permanent deformation. When fiber aspect ratio increase, $\mathrm{E} 1, \eta_{1}, \eta_{1} / E_{1}, \eta_{2} / E_{2}, \eta_{0}$, a, $\mathrm{b}$ and $\mathrm{b} / 2 \mathrm{a}$ have the similar trend with $V_{f}$ varying. When $R_{a}$ is 324 , FRAC has better resistance to elastic deformation, viscous flow deformation, viscoelastic deformation and rutting deformation capacity. The viscoelastic properties of FRAC described by the present model coincide with that performed by the creep strain-time curve shown in Fig. 6.

\section{UnloAding Phase}

$\mathrm{B}$ y using Eqn. (10) to simulate the test data, the model parameters of FRAC with different fiber volume fraction and aspect ratio are shown in Tab. 3. Obviously, it can be observed that E2, $\eta_{1}, \eta_{2}, \eta_{0}$, a, b, and c have the same pattern as that of the creep loading stage.

When fiber volume fraction and aspect ratio increase. When fiber volume fraction is $0.35 \%$ and fiber aspect ratio is 324 , $\mathrm{E} 2, \eta_{1}, \eta_{2}, \eta_{0}, \mathrm{~b}$, and $\mathrm{c}$ reach the maximum while a is the minimum. At the same time, FRAC has better deformation recovery performance. By comparing with the stage of the creep loading, the model parameters E2, $\eta_{2}$, and delay time $\eta_{2} / E_{2}$ in the unloading phase are greatly reduced, $\eta_{1}$ and $\eta_{0}$ decrease a little, while a, b, and c increase a lot. The reason is that the stage of accelerating creep is the stage of creep damage of FRAC, and after deceleration and constant velocity creep processes, its internal slippage occurs between the aggregates which result in the damage of the creep beam structure and attenuation of material properties. The actual permanent deformation characterized by the model parameters in the stage of unloading stage is bigger than the theoretical permanent deformation characterized by the same parameters in the stage of the uploading and actual deformation recovery rate is smaller than the theoretical deformation recovery rate of loading phase by the same parameter characterization, but it is not suitable to use the model parameters in the stage of creep loading to study the characteristics of the actual deformation of FRAC after unloading. From Tab. 3, it should be noticed that the correlation between the test data of unloading phase and the Eqn. (10) model decreases and 
FRAC exhibits more complex viscoelastic properties during the creep deformation recovery process after experiencing creep load damage.

\begin{tabular}{|c|c|c|c|c|c|c|c|c|c|c|c|}
\hline \multirow{2}{*}{$\begin{array}{l}V_{f} \\
/ \%\end{array}$} & \multirow[b]{2}{*}{$\mathrm{R}_{a}$} & \multicolumn{8}{|c|}{ Model parameters } & \multirow{2}{*}{$\begin{array}{c}\text { Relaxa- } \\
\text { tion } \\
\text { time } / \mathrm{s}\end{array}$} & \multirow[b]{2}{*}{$\begin{array}{l}\text { Delay } \\
\text { time/s }\end{array}$} \\
\hline & & $\begin{array}{c}\mathrm{E}_{1} \\
/ \mathrm{MPa}\end{array}$ & $\begin{array}{c}\eta_{1} \\
/ \mathrm{MPa} \cdot \mathrm{s}\end{array}$ & $\begin{array}{c}\mathrm{E}_{2} \\
/ \mathrm{MPa}\end{array}$ & $\begin{array}{c}\eta_{2} \\
/ \mathrm{MPa} \cdot \mathrm{s}\end{array}$ & $\mathrm{a} / \mathrm{s}^{-2}$ & $\mathrm{~b} / \mathrm{s}^{-1}$ & c & $\begin{array}{c}\eta_{0} \\
/ \mathrm{MPa} \cdot \mathrm{s}\end{array}$ & & \\
\hline 0 & 0 & 591 & 332893 & 143 & 4996813 & $3.04 \mathrm{E}-06$ & 0.00179 & 3.18 & $1.13 \mathrm{E}+09$ & 563 & 34943 \\
\hline 0.17 & 324 & 668 & 417152 & 156 & 8456622 & $8.21 \mathrm{E}-07$ & 0.00612 & 4.40 & $3.11 \mathrm{E}+09$ & 624 & 54209 \\
\hline 0.35 & 324 & 820 & 556709 & 171 & 17987114 & $5.30 \mathrm{E}-07$ & 0.00891 & 6.68 & $5.78 \mathrm{E}+09$ & 679 & 105188 \\
\hline 0.52 & 324 & 670 & 343284 & 129 & 6904945 & $5.81 \mathrm{E}-07$ & 0.00689 & 5.70 & $2.22 \mathrm{E}+09$ & 512 & 53527 \\
\hline 0.69 & 324 & 576 & 234039 & 107 & 2871943 & $3.54 \mathrm{E}-06$ & 0.00251 & 3.82 & $1.61 \mathrm{E}+09$ & 406 & 26847 \\
\hline 0.35 & 162 & 713 & 456829 & 158 & 15366364 & $6.60 \mathrm{E}-07$ & 0.00651 & 5.17 & $2.35 \mathrm{E}+09$ & 641 & 97255 \\
\hline 0.35 & 486 & 708 & 402514 & 142 & 6006080 & $1.15 \mathrm{E}-06$ & 0.00687 & 5.68 & $3.98 \mathrm{E}+09$ & 569 & 42296 \\
\hline 0.35 & 649 & 566 & 215312 & 108 & 2431274 & $3.10 \mathrm{E}-06$ & 0.00229 & 3.89 & $3.38 \mathrm{E}+09$ & 380 & 22512 \\
\hline
\end{tabular}

Table 2: Relationship between model parameters of Eqn. (9) with fiber contents and fiber aspect ratio.

\begin{tabular}{|c|c|c|c|c|c|c|c|c|c|c|}
\hline \multirow{2}{*}{$V_{f} / \%$} & \multirow{2}{*}{$\mathrm{R}_{a}$} & \multicolumn{7}{|c|}{ Model parameters } & \multirow{2}{*}{$\begin{array}{l}\text { Delay } \\
\text { time/s }\end{array}$} & \multirow{2}{*}{$\mathrm{R}^{2}$} \\
\hline & & $\eta_{1} / \mathrm{MPa} \cdot \mathrm{s}$ & $\mathrm{E}_{2} / \mathrm{MPa}$ & $\eta_{2} / \mathrm{MPa} \cdot \mathrm{s}$ & $\mathrm{a} / \mathrm{s}^{-2}$ & $\mathrm{~b} / \mathrm{s}^{-1}$ & $\mathrm{c}$ & $\eta_{0} / \mathrm{MPa} \cdot \mathrm{s}$ & & \\
\hline 0 & 0 & 114606 & 0.62 & 242 & 4.36E-04 & 0.97 & 210 & $4.27 \mathrm{E}+07$ & 390 & 0.98478 \\
\hline 0.17 & 324 & 318572 & 0.96 & 428 & $2.40 \mathrm{E}-04$ & 2.92 & 584 & $1.03 \mathrm{E}+08$ & 448 & 0.97522 \\
\hline 0.35 & 324 & 553520 & 1.15 & 593 & $3.17 \mathrm{E}-05$ & 4.66 & 925 & $1.51 \mathrm{E}+08$ & 515 & 0.99166 \\
\hline 0.52 & 324 & 320593 & 0.93 & 412 & $1.58 \mathrm{E}-04$ & 2.56 & 775 & $9.88 \mathrm{E}+07$ & 442 & 0.98287 \\
\hline 0.69 & 324 & 99117 & 0.61 & 218 & $3.08 \mathrm{E}-04$ & 0.73 & 544 & $3.75 \mathrm{E}+07$ & 356 & 0.98899 \\
\hline 0.35 & 162 & 211117 & 0.91 & 369 & $3.45 \mathrm{E}-04$ & 1.41 & 391 & $8.90 \mathrm{E}+07$ & 404 & 0.98453 \\
\hline 0.35 & 486 & 218774 & 0.81 & 341 & $1.95 \mathrm{E}-04$ & 1.67 & 757 & $7.20 \mathrm{E}+07$ & 423 & 0.99532 \\
\hline 0.35 & 649 & 113860 & 0.66 & 227 & $3.12 \mathrm{E}-04$ & 0.91 & 502 & $3.92 \mathrm{E}+07$ & 342 & 0.98252 \\
\hline
\end{tabular}

Table 3: Relationship between model parameters of Eqn. (10) with fiber contents and fiber aspect

\section{FRAC VisCOELASTIC CONSTITUTIVE RELATION}

$\mathrm{T}$

he above analysis shows that fiber volume fraction and aspect ratio are important factors, which affect the viscoelastic properties of the AC and the influence of fiber volume fraction and aspect ratio on the model parameters is consistent. Therefore, fiber content characteristic parameter $\lambda_{f}\left(\lambda_{f}=V_{f} \times R_{a}\right)$ can be used to represent the combined effects of the fiber volume fraction and fiber aspect ratio. By nonlinear fitting of the experimental data in this paper, the relationship between model parameters of Eqn. (9) and the fiber content characteristic parameters are as follow:

$$
\begin{aligned}
& \mathrm{E}_{1}\left(\lambda_{f}\right)=577.8+327.4 \lambda_{f}-149.1 \lambda_{f}^{2} \\
& \mathrm{E}_{2}\left(\lambda_{f}\right)=142.6+48.4 \lambda_{f}-29.7 \lambda_{f}^{2} \\
& \eta_{1}\left(\lambda_{f}\right)=324331.1+334911.7 \lambda_{f}-172179 \lambda_{f}^{2} \\
& \eta_{2}\left(\lambda_{f}\right)=4267638+17376388 \lambda_{f}-8264399 \lambda_{f}^{2} \\
& a\left(\lambda_{f}\right)=3.09 \times 10^{-6}-5.4 \times 10^{-6} \lambda_{f}+2.47 \times 10^{-6} \lambda_{f}^{2}
\end{aligned}
$$




$$
\begin{aligned}
& b\left(\lambda_{f}\right)=0.0016+0.0118 \lambda_{f}-0.005 \lambda_{f}^{2} \\
& c\left(\lambda_{f}\right)=2.88+5.32 \lambda_{f}-2.18 \lambda_{f}^{2} \\
& \eta_{0}\left(\lambda_{f}\right)=1.11 \times 10^{9}+5.92 \times 10^{9} \lambda_{f}-2.7 \times 10^{9} \lambda_{f}^{2}
\end{aligned}
$$

The relationship between model parameters of Eqn. (10) and the fiber content characteristic parameter are as follow:

$$
\begin{aligned}
& \mathrm{E}_{2}\left(\lambda_{f}\right)=0.615+0.884 \lambda_{f}-0.401 \lambda_{f}^{2} \\
& \eta_{1}\left(\lambda_{f}\right)=97153.9+675179.3 \lambda_{f}-305297 \lambda_{f}^{2} \\
& \eta_{2}\left(\lambda_{f}\right)=232.1+559.4 \lambda_{f}-256.2 \lambda_{f}^{2} \\
& a\left(\lambda_{f}\right)=4.5 \times 10^{-4}-5.9 \times 10^{-4} \lambda_{f}+2.37 \times 10^{-4} \lambda_{f}^{2} \\
& b\left(\lambda_{f}\right)=0.89+5.74 \lambda_{f}-2.64 \lambda_{f}^{2} \\
& c\left(\lambda_{f}\right)=191.1+1027 \lambda_{f}-391.6 \lambda_{f}^{2} \\
& \eta_{0}\left(\lambda_{f}\right)=4.01 \times 10^{7}+1.75 \times 10^{8} \lambda_{f}-8 \times 10^{7} \lambda_{f}^{2}
\end{aligned}
$$

By substituting Eqn. (14)-(21) and (22)-(28) into (9) and (10) respectively, the creep equations of present model of FRAC with consideration of fiber content characteristic parameter effect can be obtained:

Load phase:

$$
\varepsilon\left(t, \lambda_{f}\right)=\sigma_{0}\left[\frac{1}{\mathrm{E}_{1}\left(\lambda_{f}\right)}+\frac{t}{\eta_{1}\left(\lambda_{f}\right)}+\frac{1-e^{-t \tau}}{\mathrm{E}_{2}\left(\lambda_{f}\right)}+\frac{\frac{a\left(\lambda_{f}\right)}{3} t^{3}-\frac{b\left(\lambda_{f}\right)}{2} t^{2}+c\left(\lambda_{f}\right) t}{\eta_{0}\left(\lambda_{f}\right)}\right]
$$

Unload phase:

$$
\varepsilon\left(t, \lambda_{f}\right)=\sigma_{0}\left[\frac{t_{0}}{\eta_{1}\left(\lambda_{f}\right)}+\frac{\left(1-e^{-t_{0} \tau}\right) e^{-\tau\left(t-t_{0}\right)}}{\mathrm{E}_{2}\left(\lambda_{f}\right)}+\frac{\frac{a\left(\lambda_{f}\right)}{3} t_{0}^{3}-\frac{b\left(\lambda_{f}\right)}{2} t_{0}^{2}+c\left(\lambda_{f}\right) t_{0}}{\eta_{0}\left(\lambda_{f}\right)}\right]
$$

where, $\tau=\frac{E_{2}\left(\lambda_{f}\right)}{\eta_{2}\left(\lambda_{f}\right)}$.

Taking derivative of $t$ in Eqn. (29) and (30), differential constitutive equation of FRAC can be obtained, which is characterized by the present model and considered the influence of fiber content characteristic parameter:

Load phase: 


$$
d \varepsilon\left(t, \lambda_{f}\right) / d t=\dot{\varepsilon}\left(t, \lambda_{f}\right)=\sigma_{0}\left[\frac{1}{\eta_{1}\left(\lambda_{f}\right)}+\frac{e^{-t \tau\left(\lambda_{f}\right)}}{\eta_{2}\left(\lambda_{f}\right)}+\frac{a\left(\lambda_{f}\right) t^{2}-b\left(\lambda_{f}\right) t+c\left(\lambda_{f}\right)}{\eta_{0}\left(\lambda_{f}\right)}\right]
$$

Unload phase:

$$
d \boldsymbol{\varepsilon}\left(t, \lambda_{f}\right) / d t=\dot{\varepsilon}\left(t, \lambda_{f}\right)=\sigma_{0}\left[\frac{\left(e^{-t_{0} \tau\left(\lambda_{f}\right)}-1\right) e^{-\tau\left(t-t_{0}\right)}}{\eta_{2}\left(\lambda_{f}\right)}\right]
$$

Fig. 8 displayed the variation of the creep strain and fiber content characteristic parameter with different loading stress and time, which is derived from Eqn. (29). It can be seen that the creep strain increases with the increase of loading stress and prolonged the load time, while it firstly decreases and then increases with the increase of the fiber content characteristic parameter. It should be noted that when fiber content characteristic parameter is 1.13 , the creep strain with different loading stress and the loading time achieved the minimum, at this time the FRAC exhibits good deformation resistance.

The variation between the value of creep speed and the fiber content characteristic parameter in the stage of loading, derived from Eqn. (31), is shown in Fig. 9. It can be seen that the creep speed increases with the increase of load stress, while the creep rate firstly decreases and then increases with the increase of fiber content characteristic parameter under the same loading conditions. It should be noted that when fiber content characteristic parameter is 1.13 under different creep load, the rate of creep deformation reaches minimum. It can also be noticed that, the creep rate gradually decreases firstly and then goes to a stable value. Finally, the creep rate increases with the increase of load time. It is worth to mentioning that the above phenomenon is consistent with the three-phase character of the creep curve in the stage of loading from test.

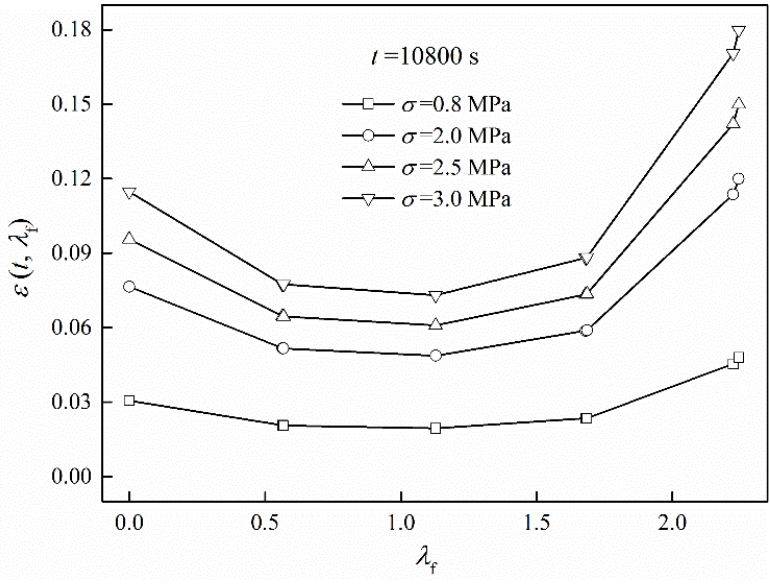

Figure 8(a): Different stress.

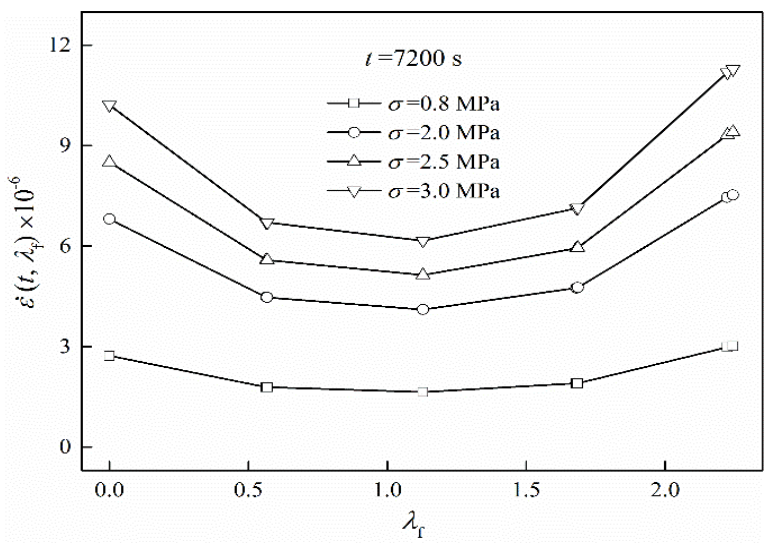

Figure 9: Relationship between creep speed and $\lambda_{f}$.

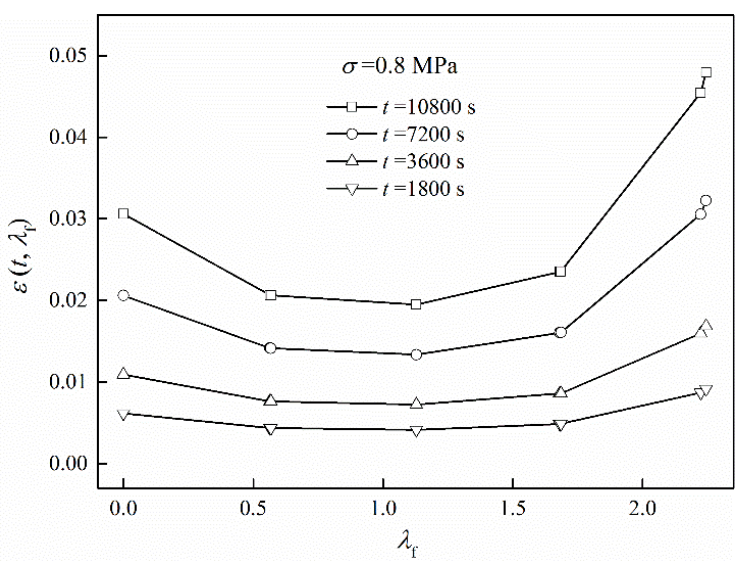

Figure 8(b): Different loading time

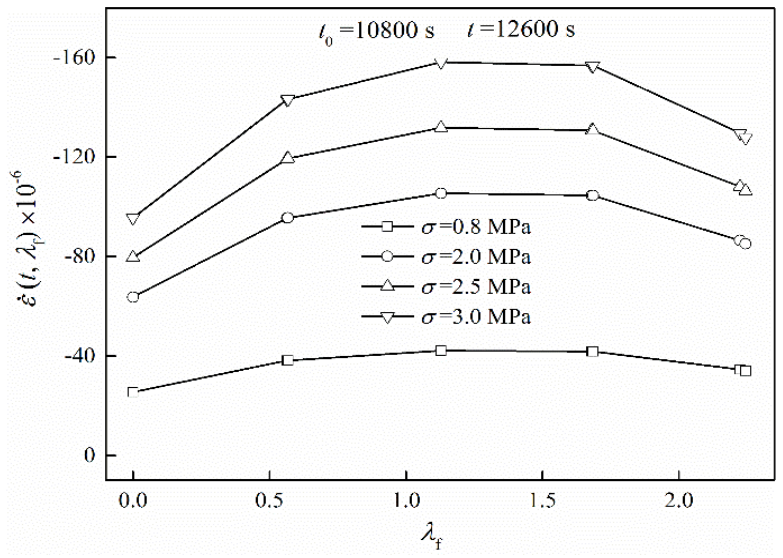

Figure 10: Relationship between creep speed and $\lambda_{f}$. 
The variations of the creep strain with the fiber content characteristics for 4 loads in unloading phase are plotted in Fig. 10. It can be observed that within 30min after unloading, the greater the stress is, the greater both the damage of the FRAC at creep loading process and residual creep strain is. At the same time, the larger the loading stress is, the greater the elastic deformation is, and as a result, the inertia of the recovery elastic deformation after unloading causes that the recovery creep rate increases with the increase of stress. It should be mentioned that the residual strain of FRAC under the same creep loading stress decreases firstly and then increases with the increase of the fiber content characteristic parameter after unloading, while the creep recovery rate increases firstly and then decreases under the same condition. In addition, when the fiber content characteristic parameter is about 1.13, the residual creep strain of FRAC is at minimum and the creep deformation recovery rate reaches maximum, the FRAC shows better recovery performance of the viscoelastic deformation in this case. It can be concluded from Eqn. (32) that the viscoelastic deformation recovery rate decreases gradually at the beginning with the uninstall time elapsing, and then goes to a stable value, that is consistent with test results.

\section{CONCLUSIONS}

B y adding viscous unit into Burgers model, the new model with five units and eight parameters can effectively present the deformation characteristics of FRAC during the whole creep process in the stage of loading. The rheological time of FRAC calculated from the model is consistent with that from test results, and the curves from the present model coincide well with the curve of tests.

The creep tests of FRAC show that with the increase of fiber content and aspect ratio, FRAC beam the curve of bottom flexural tensile strain and time is firstly reduced and then elevated. When the fiber content is $0.35 \%$ and its aspect ratio is 324 , corresponding curves of creep deformation and time are in the lowest position and FRAC has a larger resistance to deformation, which is consistent with the influence of the fiber content and aspect ratio on the viscoelastic properties of AC obtained from the present model.

Fiber content characteristic parameter can comprehensively reflect the effect of fiber content and aspect ratio. The differential constitutive equation of FRAC performed through the present model by considering the influence of fiber content characteristic parameter can be characterized by Eqn. (31) and (32). Both the theoretical analysis and experimental studies show that: the creep strain, creep speed, the damage in FRAC, and the residual strain after unloading increase with the increasing of the loading stress and the loading time. It should be mentioned that under the same condition of load stress, the load creep strain, creep rate, and residual strain after unloading decreases firstly and then increases with the increase of fiber content characteristic parameter, while creep deformation recovery rate increases firstly and then decreases with the increase of fiber content characteristic parameter. When the fiber content characteristic parameter is 1.13, FRAC has better abilities of both anti-deform and creep deformation recovery.

\section{ACKNOWLEDGMENTS}

he authors gratefully acknowledge the financial support of the project from the Colleges and Universities Key Scientific Research Projects of Henan Province (Grant No. 16B580003) and Horizontal Research Project of Xuchang University (Grant No. 2017HX029).

\section{REFERENCES}

[1] Popoola, A. O., Baoku, I. G. and Olajuwon, B. I., (2016). Heat and mass transfer on MHD viscoelastic fluid flow in the presence of thermal diffusion and chemical reaction, International Journal of Heat and Technology, 34, pp. 15-26.

[2] Xu, S. F. (1992). A rheological model representing the deformation behavior of asphalt mixtures, Mechanics and Engineering, pp. 1437-1440.

[3] Yang, T. Q. (1990). Viscoelastic mechanics, Central China University of Technology Press, Wuhan.

[4] Yang, Y. (2009). Experience study on the visco-elastoplastic constitute model of asphalt mixture, Huazhong University of Science and Technology, Wuhan.

[5] Mitra, K., Das, A., Basu, S. (2012). Mechanical behavior of asphalt mix: An experimental and numerical study, Construction and Building Materials, 27, pp. 545-552. 
[6] Bandyopadhyaya, R., Das, A. and Basu, S., (2008). Numerical simulation of mechanical behaviour of asphalt mix, Construction and Building Materials, 22, pp. 1051-1058.

[7] González, J.M., Miquel Canet, J., Oller, S. and Miró, R. (2007). A viscoplastic constitutive model with strain rate variables for asphalt mixtures-numerical simulation, Computational Materials Science, 38, pp. 543-560.

[8] Guo, N. S., Zhao and Y. H. (2004). Study on creep performance of fiber reinforced asphalt concrete, Journal of China \& Foreign Highway, 1, pp. 124-127.

[9] Rahmani, E., Darabi, M. K., Abu Al-Rub, R. K., Kassem, E., Masad, E. A. and Little, D. N. (2013). Effect of confinement pressure on the nonlinear-viscoelastic response of asphalt concrete at high temperatures, Construction and Building Materials, 47, pp. 779-788.

[10] Stastna, J., Zanzotto, L. and Vacin, O. J. (2003). Viscosity function in polymer-modified asphalts, Journal of Colloid and Interface Science, 259, pp. 200-207.

[11] Sun L. and Zhu, Y. (2013). A serial two-stage viscoelastic-viscoplastic constitutive model with thermodynamical consistency for characterizing time-dependent deformation behavior of asphalt concrete mixtures, Construction and Building Materials, 40, pp. 584-595.

[12] Ming, Z. H., Huang, W. and Qian, Z. D. (2007). Analysis on mechanics model of viscoelasticity behaviors for epoxy resin asphalt mixture, Journal of Highway and Transportation Research and Development, 24(6-9), pp. 34.

[13] Ministry of Transport of the People's Republic of China, Standard test methods of bitumen and bituminous mixtures for highway engineering, JTG E20-2011, China Communications Press, Beijing, (2001).

\section{NomenClature}

$\begin{array}{ll}R_{t} & \text { Rheological time }(\mathrm{s}), F_{t}=t^{*} \\ \sigma_{0} & \text { Creep test loading stress } \\ E_{1}, E_{2} & \text { Elastic modulus of elements } 1 \text { and } 2(\mathrm{MPa}) \\ \eta_{1}, \eta_{2}, \eta_{3} & \text { Viscosities of elements } 3,4 \text { and } 5(\mathrm{MPa} \cdot \mathrm{s}) \\ \tau & E_{2} / \eta_{2}\left(\mathrm{~s}^{-1}\right) \\ A, B & \text { The viscosity coefficient of element } 4 \\ \eta_{0} & \text { Initial viscosity of element } 5 \\ a, b, c & \text { Viscosity coefficient of element } 5 \\ \varepsilon(t) & \text { Creep strain } \\ \dot{\varepsilon}(t) & \text { Creep speed } \\ \ddot{\varepsilon}(t) & \text { Acceleration of creep } \\ t^{*} & \text { Solution of formula (13), } \mathrm{R}_{t}=t^{*} \\ \mathrm{R}_{T} & \text { Relaxation time (s): } \eta_{1} / \mathrm{E}_{1} \\ D_{T} & \text { Delay time (s): } \eta_{2} / \mathrm{E}_{2} \\ \mathrm{R}_{a} & \text { Ratio of fiber length to diameter } \\ P_{f} & \text { Fiber content: fiber to mineral mass ratio } \\ V_{f} & \text { Volume ratio of fiber to mixture } \\ d(t) & \text { Creep trabecular mid-span deflection } \\ R^{2} & \text { Square of correlation coefficient } \\ \lambda_{f} & \text { Fiber content characteristic parameter, } \lambda_{f}=V_{f} \times \mathrm{R}_{a} \\ \varepsilon\left(t, \lambda_{f}\right) & \text { The creep strain when characteristic parameter of fiber content is } \lambda_{f} \text { and time is } \mathrm{t} \\ \dot{\varepsilon}\left(t, \lambda_{f}\right) & \text { The Creep velocity when characteristic parameter of fiber content is } \lambda_{f} \text { and time is t } \\ \sigma_{0} & \text { Loading stress (MPa) }\end{array}$

